\title{
Expediente e Apresentação
}

RELAEC: Revista Latino-Americana de Estudos Científicos

Universidade Federal do Espirito Santo - UFES

Reitor

Paulo Sérgio de Paula Vargas

Vice-Reitor

Roney Pignaton da Silva

Editor Responsável da RELAEC

Yuri Miguel Macedo

Universidade do Estado da Bahia - UNEB

Reitor

José Bites de Carvalho

Editores Responsáveis na RELAEC

Helder Bomfim e Aline Batista Moscovits

Universidade Federal do Vale do São Francisco - UNIVASF

\author{
Reitor \\ Paulo César Fagundes Neves \\ Vice-Reitor \\ Valdner Daizio Ramos Clementino \\ Editor Responsável da RELAEC \\ Ramon Missias-Moreira
}

\section{Universidade Federal da Bahia - UFBA}

\author{
Reitor \\ João Carlos Salles Pires da Silva \\ Vice-Reitor \\ Paulo César Miguez de Oliveira \\ Editora Responsável da RELAEC \\ Bianca Rückert
}


Revista Encantar: Educação, Cultura e Sociedade

Universidade Federal do Espirito Santo - UFES

Universidade do Estado da Bahia - UNEB

Universidade Federal do Vale do São Francisco - UNIVASF

Universidade Federal da Bahia - UFBA

Vitória, Espirito Santo, Brasil

http://www.periodicos.ufes.br/ipa

relaec.revista@gmail.com

Dados internacionais de catalogação na publicação (CIP)

RELAEC: Revista Latino-Americana de Estudos Científicos [on line] / Universidade Federal do Espirito Santo, Universidade do Estado da Bahia, Universidade Federal do Vale do São Francisco e Universidade Federal da Bahia - Ano 1, V. 5 (Setembro/Outubro.2020). Vitoria: UFES-UNEB-UNIVASF-UFBA, 2020.

2020 - Fluxo Contínuo

ISSN: 2675-3855

DOI: $10.46375 /$ relaec

1. Educação. 2. Ciências Sociais. 3. Interdisciplinar

CDD: 370 


\section{Apresentação}

A RELAEC - Revista Latino-Americana de Estudos Científicos é um periódico interinstitucional (UFES, UNEB, UNIVASF e UFBA) e de fluxo continuo que aceita a colaboração livre de textos inéditos, de reconhecido interesse acadêmico e atualidade das ciências, na forma de artigos, ensaios bibliográficos e resenhas. Cada número contém um dossiê sobre tema específico organizado a partir de autores convidados, de reconhecida experiência acadêmica, e que represente contribuição original ao debate, os quais são igualmente submetidos ao processo de revisão pelos pares.

Em ambos os casos é imprescindível que os trabalhos sejam enviados para os editores em sua forma final, apresentem consistência teórica, coerência quanto às fundamentações e alguma originalidade. Informações técnicas devem ser evitadas no corpo do texto e se limitarem ao fundamental. Os artigos não devem ser submetidos simultaneamente pelo autor a mais de um periódico no Brasil.

A publicação dos textos está condicionada a pareceres do Conselho Editorial, garantindo o anonimato de autores e avaliadores. Eventuais sugestões de modificação de estrutura ou conteúdo, por parte da Editoria, serão previamente acordadas com os autores. Não serão admitidos acréscimos ou modificações depois que os trabalhos forem entregues para composição final. 


\section{Editora-Chefe 2020}

Aline Batista Moscovits - UNEB

\section{Editores Adjuntos}

Bianca Rückert - UFBA

Helder Freitas do Bomfim - UNEB/UFBA

Ramon Missias-Moreira - UNIVASF

Yuri Miguel Macedo - UFES/UFSB

\section{Editores Assistentes}

Elisabete Tâmara Galvão dos Santos - UESB/UNEB

Felipe Moraes dos Santos - UFPA

Felipe Moraes dos Santos - UFPA

Ismael Krüger Pescke - UFRGS

Jean Carlos da Silva Monteiro - UFMA

João Carlos Botelho - IFTO

Margeylson Ribeiro da Graça - IFBA

Maria Rilda Alves da Silva Martins - IFTO

Omar Farid Bustos Tobón - Instituto Politécnico Nacional - México

Thiago da Silva Ferreira - UFRJ

\section{Conselho Científico}

Adriano Pereira Jardim - UFES - Brasil

Alexsandra dos Santos Oliveira - UFF - Brasil

Eliana Mariel Diez de los Ríos - Fundación Barceló - Argentina

Eliana Povoas Pereira Estrela Brito - UFSB - Brasil

Elisa Ramalho Ortigão - FAPES -Brasil

Elói Martins Senhoras - UFRR - Brasil

Kiusam de Oliveira - USP/ Osibàtá Produções - Brasil

Leandra Gonçalves dos Santos - PMV e PMC - Brasil

Lívia Santana e Sant'Anna Vaz - Ministério Publico da Bahia - Brasil

Lúcia Gracia Ferreira Trindade - UFRB - Brasil

Maria de Fátima Hanaque Campos - UNEB - Brasil

Rita de Cássia Vasconcelos da Costa - FIOCRUZ - Brasil

Silvia Lúcia Lopes Benevides - UNEB - Brasil

Sônia Guimarães - ITA - Brasil 